\title{
Cytochrome P-450 Gene Expression in the Functional Units of the Fetal Liver
}

\author{
Jose Chianale, $\dagger$ Caroline Dvorak, Donna L. Farmer, Linda Michaels and Jorge J. Gumucio \\ Department of Internal Medicine, Section of Gastroenterology, Veterans Administration Medical Center, The University of \\ Michigan, Ann Arbor, Michigan 48105 and the Department of Anatomy, Chicago College of Osteopathic Medicine, \\ Chicago, Illinois
}

\begin{abstract}
Hepatocytes of the right and left lobes of the fetal liver are surrounded by different microenvironments. The right and left lobes of the fetal liver are perfused by vascular systems carrying different concentrations of oxygen and constitute distinct functional units. The aim of this study was to assess the expression of the phenobarbital-inducible cytochrome P-450 b,e genes in hepatocytes of the right and left fetal liver lobes in mice. Northern-blot analysis using $\left[{ }^{32} P\right]$ CDNAs and quantitative dot-blot hybridization were performed to assess the size and levels of these mRNAs in the right and left fetal liver lobes. In fetal mice, the levels of cytochrome P450, b,e mRNAs were higher in the left than in the right fetal liver lobe. During the last days of gestation and in the immediate postnatal period, the levels of liver cytochrome $P-450$ b,e mRNAs increased predominantly in the left liver lobe. In contrast, the levels of albumin and $\alpha$-fetoprotein mRNAs (genes studied to assess the specificity of these findings) were similar in each of functional units of the fetal liver. Phenobarbital induction of cytochromes $P-450$ b,e mRNAs was not observed in either of the fetal liver lobes. Postnatally, phenobarbital induced these cytochromes similarly in the right and left liver lobes. Therefore, the microenvironment surrounding fetal hepatocytes seems to influence the expression of the cytochrome P-450 b,e genes. This lobar heterogeneity of expression disappears as the pattern of adult liver circulation is attained.
\end{abstract}

The adult pattern of gene expression in liver is attained by various regulatory steps occurring in the developing liver. In this study, attention was focused on three periods: gene expression in the fetal liver units; during the transition from fetal to newborn, and finally, during the maturation of the newborn liver. In fetal life, the liver receives its blood supply mainly from the umbilical vein and the portal vein while the hepatic artery contributes

Received March 18, 1987; accepted September 1, 1987.

† Present address: Department of Medicine, Section of Gastroenterology, Catholic University of Chile, Marcoleta 347, Santiago, Chile.

This study was funded in part by the Veterans Administration Merit Review Award, by Grant AM 32842 from the National Institutes of Health and by a fellowship from the American Liver Foundation (to J. Chianale).

Address reprint requests to: Jorge J. Gumucio, M.D., Department of Internal Medicine, Section of Gastroenterology (111D), Veterans Administration Medical Center, 2215 Fuller Road, Ann Arbor, Michigan 48105 . minimally to liver blood flow (1). Studies performed during fetal life in humans (2), lambs (3) and sheep (4, 5) have indicated that the umbilical vein supplies the left and medial aspects of the fetal liver while the right lobe is perfused by the fetal portal vein. Since the $\mathrm{pO}_{2}$ of umbilical vein blood is about 40 torr and most likely rich in maternal hormones, and that of portal vein blood is about 20 torr (1) and probably containing gastrointestinal hormones of fetal origin, there is a microenvironmental heterogeneity around hepatocytes of the right and left fetal liver lobes. In addition, it has been proposed that there is a greater hematopoietic activity in the right than in the left fetal liver lobe (6). Immediately after birth, the newborn liver undergoes a process of rapid adaptation to changes in liver circulation. Blood flow through the umbilical vein is interrupted, the entire liver is suddenly perfused via the portal vein and the hepatic artery, and finally, there is progressive closure of the ductus venosus $(7,8)$.

Higher levels of total cytochrome $\mathrm{P}-450$ protein have been observed in the left than in the right fetal liver lobe in monkeys (9). Moreover, faster rates of uptake and drug biotransformation in the left than in the right fetal liver lobes have been reported $(10,11)$.

The purpose of this study was to assess the expression of the phenobarbital (PB)-inducible cytochromes P-450 b,e genes in the right and left lobes of the fetal liver in control and PB-treated mice. To assess the species specificity of the differences in gene expression between the functional units of the fetal liver, mRNA measurements were also performed in fetal rat liver. To determine the gene specificity in expression, albumin and $\alpha$-fetoprotein mRNAs were measured in the right and left fetal liver lobes. Finally, the changes in the expression of these genes in each liver lobe during the transition from fetal to newborn and to adult liver were also studied.

\section{MATERIALS AND METHODS}

\section{Quantitation of Cytochrome P-450 b,e mRNAs, Albumin $m R N A$ and $\alpha$-Fetoprotein $m R N A$}

$\mathrm{C} 3 \mathrm{H}$-timed pregnant mice were used as the source of fetal and newborn livers. Male mice of about 25 to $30 \mathrm{gm}$ were the source of adult mice livers. Sprague-Dawley timed-pregnant rats were used in the studies involving fetal fetal and newborn rat livers. 
Pregnant mice or rats of 17, 18 and 19 days gestation (exact time of gestation described in legends to pertinent figures), newborns 3, 10 and 20 days old and adults received $\mathrm{PB}$ as a single dose $(60 \mathrm{mg} \times \mathrm{kg}$, i.p.) $16 \mathrm{hr}$ before the experiment. This time interval was chosen because it represents the time of maximal induction of cytochrome P-450 b,e mRNAs in the adult liver $(12,13)$. Controls received an equal volume of 0.15 $M \mathrm{NaCl}$ (i.p.) Animals were not fasted prior to the experiments. Under ether anesthesia, livers were removed and rapidly immersed in liquid nitrogen, weighed and homogenized in guanidinium isothiocyanate (14). In fetuses, the right lobe was exposed by displacement of the medial and left lobes to the left of the abdomen. The right lobe is located in the right upper quadrant of the abdomen and posteriorly. This lobe can also be identified because a branch of the bile duct drains this lobe separately. The right lobe was removed and processed separately from the remaining liver parenchyma. The middle and left lobes were removed together and have been described as "left liver lobe." In experiments involving fetal livers, the right or left lobe of about 10 fetuses (usually corresponding to two pregnant mice or rats) were pooled. In experiments with newborn livers, usually 3 to 5 newborn right or left liver lobes of identical age were pooled.

RNA Extraction: RNA was extracted from the right and left liver lobes of: (a) mouse fetuses of 18 and 19 days gestation; (b) rat fetuses of 17, 18 and 19 days gestation; (c) newborn mice and rats 3,10 and 20 days old, and (d) adult mice and rats. RNA was extracted by the method of Chirgwin et al. (14). At the end of the extraction procedure, the 260/280 absorbance ratio of the RNA sample was measured. Only samples with a $260 / 280$ ratio above 1.8 were used. If the ratio was lower, the sample was reextracted by the same method. In some experiments involving the measurement of cytochrome $\mathrm{P}-450 \mathrm{~b}, \mathrm{e}$ mRNAs in rat liver, poly $\left(\mathrm{A}^{+}\right) \mathrm{RNA}$ was isolated from fetal rat livers using poly(U) paper (Hybond-m AP paper, Amersham Corp., Chicago, Ill.) $(15,16)$.

Northern Blots: The size of the mRNA hybridizing to each of the probes was assessed by Northern-blot analysis using RNA extracted from fetal and adult livers as described (17), and previously used in this laboratory (12).

Quantitative Dot-Blot Hybridization: Measurements of the relative content of specific mRNAs were performed by quantitative dot-blot hybridization. The method used was a modification of that of Papavasiliou et al. (18).

Standardization of the Assay: Conditions were assessed to assure that the concentration of labeled DNA probes was always in excess and thus, not rate-limiting. For this purpose, for each of the probes used, a series of preliminary experiments were performed in which different amounts of RNA were hybridized with various concentrations of probe. In these and in subsequent experiments, the area of the nitrocellulose filter was kept constant. Aliquots of total cellular RNA or poly $\left(\mathrm{A}^{+}\right) \mathrm{RNA}$ were adjusted with sterile water, $37 \%$ formaldehyde and $20 \times$ standard saline citrate [(SSC) $0.15 \mathrm{M} \mathrm{NaCl}$ and $0.015 M$ sodium citrate] to a final concentration of $7.4 \%$ formaldehyde and $6 \times \mathrm{SSC}$. The samples were heated at $60^{\circ} \mathrm{C}$ for 15 min (19). Further dilutions of this solution were made using 15X SSC and spotted on nitrocellulose filter paper (BA 85, Schleicher and Schuell, Keene, NH) using a Minifold II system. Linearity of the assay was tested in every experiment by spotting each denatured RNA or poly $\left(\mathrm{A}^{+}\right) \mathrm{RNA}$ sample on nitrocellulose paper in six concentrations: $0.5,0.75,1.0,1.5,2.0$ and $2.5 \mu \mathrm{g}$ per spot for total RNA and $0.5,0.75,1.0,1.5,1.75$ and $2.0 \mu \mathrm{g}$ per spot for poly $\left(\mathrm{A}^{+}\right) \mathrm{RNA}$. The filters were air-dried and baked at $80^{\circ} \mathrm{C}$ under vacuum for $2 \mathrm{hr}$.

An internal standard (RNA extracted from adult liver treated with $\mathrm{PB}$ ) was also spotted in six concentrations in each of the filters assessed. This allowed the assessment of the reproduci- bility of the amount of RNA spotted, that of the blotting procedure and the hybridization itself. Experiments in which the slope of the internal standard departed from the values usually obtained were discarded and the dot-blot hybridization repeated.

cDNA Probes: The cytochrome P-450 b,e probe used in these experiments was a generous gift of the Dr. M. Adesnik (New York University). This clone (R17) consists of a 1,100 b.p. cDNA cloned into pBR322. This cDNA codes for the 211 amino acids of the $3^{\prime}$-carboxyterminal end of a polypeptide corresponding to cytochrome P-450 e (20). However, due to the homology between cytochromes $\mathrm{P}-450 \mathrm{~b}, \mathrm{e}$, this cDNA recognizes sequences of both cytochromes P-450 b,e mRNAs. Consequently, in this study, the measured levels of cytochrome P$450 \mathrm{mRNA}$ have been expressed as if both cytochrome P-450 mRNAs were assessed simultaneously. Therefore, measurements have been described in the text as "cytochrome P-450 b,e mRNAs." In these experiments, the cDNA insert was isolated from R17 using DEAE membranes (Schleicher and Schuell). In initial experiments involving labeling of this rat liver cDNA probe by nick translation $(17,21)$, the levels of cytochrome P-450 b,e mRNAs detected in control and PBinduced mouse livers were close to background, raising the possibility that the probe was not cross-reacting with mouse liver. Subsequently, this rat liver cDNA was labeled using the "oligolabeling" method (22). With this method, the specific activities of the probes were 10 - to 20 -fold higher than the specific activities obtained by nick translation. Northern-blot analysis using the cytochrome P-450 b,e (R17) cDNA labeled to this high specific activity showed that this probe crosshybridized with mouse liver RNA, a result that was not previously apparent when nick-translated probes were used. The cross-hybridization of this probe with mouse liver has been described (23).

Albumin Probe: A mouse liver albumin cDNA, a generous gift from Dr. S. Tilghman (24), corresponds to the pmalb 2 clone. The cDNA insert is 700 b.p. and is cloned into pBR322. The cDNA insert was separated from pBR322 by the aforementioned DEAE membrane method. This probe cross-reacted with rat liver albumin mRNA. Therefore, this probe was used in measurements of albumin mRNA both in mouse and in rat liver.

$\alpha$-Fetoprotein Probe: The cDNA insert of clone pafp 3 isolated from mouse liver by Tilghman and Belayew (24) was separated from the vector as previously described. This probe did not cross-react with rat liver $\alpha$-fetoprotein mRNA.

$\beta$-Major Globin Probe: Mouse genomic DNA representing the gene coding for $\beta$-major globin, the major hemoglobin expressed in fetal life, was a generous gift of Dr. F. Collins (Department of Human Genetics, The University of Michigan). This gene was cloned into pBR325 and is about $1.5 \mathrm{~kb}$.

Labeling of the cDNAs: Initially, nick translation (BRL nick translation kit) $(17,21)$ using $\left[\alpha-{ }^{32} \mathrm{P}\right]$ dATP (Amersham Corp.; 3,000 Ci per mmole) was used to label each cDNA. As mentioned, in later experiments and to assess the cross-reactivity of the R17 cDNA with mouse liver, this insert was also labeled using the "oligolabeling" method (Klenow fragment, BRL, Gaithersburg, Md.) (13). This method resulted in specific activities around $2 \times 10^{9} \mathrm{cpm}$ per $\mu \mathrm{g}$ DNA.

\section{Hybridization}

The baked nitrocellulose filters were prehybridized and hybridized (17). Hybridizations were performed at $65^{\circ} \mathrm{C}$ for $16 \mathrm{hr}$ in a solution $\left(0.1 \mathrm{ml}\right.$ per $\mathrm{cm}^{2}$ of filter) containing: $0.9 \mathrm{M} \mathrm{NaCl}$, $0.1 \mathrm{M}$ sodium citrate, $0.5 \%$ sodium dodecyl sulfate (SDS), $5 \times$ Denhardt's solution, $0.01 M$ EDTA, $100 \mu \mathrm{g}$ per ml denatured salmon sperm DNA and between 20 and $30 \mathrm{ng}$ per ml $\left[\alpha^{-32} \mathrm{P}\right]-$ 
labeled insert, depending on the probe (exact concentrations provided in the legends to figures). Filters were washed sequentially in: (a) $2 \times \mathrm{SSC}, 0.5 \% \mathrm{SDS}$ for $10 \mathrm{~min}$ at room temperature; (b) $2 \times \mathrm{SSC}, 0.1 \% \mathrm{SDS}$ for $10 \mathrm{~min}$ at room temperature and (c) $0.1 \times \mathrm{SSC}, 0.5 \% \mathrm{SDS}$ for $2 \mathrm{hr}$ at $65^{\circ} \mathrm{C}$. Filters were washed in fresh buffer $(0.1 \times \mathrm{SSC}, 0.5 \%$ SDS) for an additional $30 \mathrm{~min}$. After washings, autoradiographs were performed at $-70^{\circ} \mathrm{C}$, using Kodak X-Omat AR film between two intensifying screens. Densitometric analysis of autoradiographs was performed using a laser-activated LKB densitometer (LKB Instruments, Inc., Gaithersburg, Md.) linked to an Apple IIe computer. Integration of areas under peaks, and the corresponding statistical analysis, was performed using Gelscan program (LKB software). Immediately after the autoradiography was obtained (usually 2 to $24 \mathrm{hr}$ of exposure), spots on filters were cut out and counted in scintillation vials using Aquasol (Dupont, Boston, Mass.) as the scintillation fluid.

\section{Assessment of Background and Nonspecific Hybridization}

Background was assessed by counting a cut out of nitrocellulose paper from an area of the filter not spotted with RNA. In performing densitometric analysis of autoradiographs, background (density of the autoradiograph in areas not spotted with RNA) was substracted before the area of each peak was calculated. Nonspecific hybridization was assessed using RNA extracted from fetal sternum and anterior chest wall, tissue thought not to contain the mRNAs to be measured. In addition, hybridizations were performed using $\left[\alpha{ }^{32} \mathrm{P}\right] \mathrm{pBR} 322$.

\section{Calculation of Results}

Results were calculated using data generated by both the radioactive measurements as well as by the densitometric analysis. Linearity was assessed by linear regression analysis performed by the least-squares method. Only data with a correlation coefficient $(\mathrm{r})$ of 0.9 or higher were used in the calculations. Results have been expressed in arbitrary densitometric units.

\section{Assessment of the Relative Content of Hematopoietic Cells in the Right and Left Fetal Liver Lobes}

Mouse genomic DNA representing the gene coding for $\beta$ major globin, the major hemoglobin expressed in fetal life, was used to assess the relative content of globin (and thus, presumably of hematopoietic cells) in each fetal liver lobe. The rationale for these experiments was to determine whether variations in the relative content of hematopoietic cells between the right and left fetal liver lobes may explain the differences in levels of specific mRNAs observed when the data were expressed per microgram of RNA extracted. In addition, a qualitative assessment of the relative distribution of hematopoietic cells in the right and left fetal liver lobes was performed by light microscopy. In this case, $\mathrm{H} \& \mathrm{E}$-stained sections were prepared from livers of fetuses (18 and 19 days gestation), newborns 3 and 10 days old, and adult mouse liver.

\section{Characterization of the Vascular Pattern of Fetal Mouse Liver: Microvascular Casts}

To characterize the vascular system in fetal mouse liver, microvascular injections of India ink in mice of 20 days gestation were performed. Pregnant dams were anesthetized with ether, the abdomen opened and the uterine horns exposed. After incision on the antemesometrial border, a single fetus was removed with fetal membranes and placenta still intact. The uterine horns were moistened with warm $0.15 \mathrm{M} \mathrm{NaCl}$ and covered until the next fetus was removed. Each fetus was placed in a watch glass, filled with warm sterile $0.15 \mathrm{M} \mathrm{NaCl}\left(37^{\circ} \mathrm{C}\right)$ and examined under the dissecting microscope. The fetal membranes were dissected away, being careful to leave the placental circulations (chorioallantoic and vitelline) undisturbed. Only living fetuses, as determined by an active heart beat, were used. India ink casting solution, consisting of $100 \%$ carbon particles in 0.15 $M \mathrm{NaCl}$ (Hunt Speed Ball, Hunt Manufacturing Company, North Carolina), was sonicated for $45 \mathrm{~min}$ and diluted to a $3 \%$ v:v solution with warm $0.15 \mathrm{M} \mathrm{NaCl}$. A hand-drawn micropipet attached to a Brinkman 8040 micromanipulator was driven into either the left ventricle or umbilical vein. The injection material was mouth-blown and the process repeated several times until the entire vascular system was filled with India ink. The fetus was placed in $35 \%$ ethanol for $1 \mathrm{hr}$, followed by immersion in $70 \%$ ethanol overnight. Dehydration of fetuses was continued through a series of graded ethanol and placed in methylsalicylate for clearing and storage. Cleared fetuses were examined under a Wild M7S stereo dissecting microscope with transmitted illumination. Vascular patterns were analyzed and recorded graphically.

\section{RESULTS}

\section{Northern Blots}

Figure 1 shows that the size of the mRNA which hybridized to the cytochrome P-450 b,e (R17) cDNA in fetal and adult mouse livers corresponded to about 1.8 $\mathrm{kb}$ and was similar in size to the rat liver RNA hybridizing to this cDNA. Northern blots were also performed with albumin, $\alpha$-fetoprotein and $\beta$-major globin cDNAs using RNA extracted from mouse and rat livers (fetal and adult livers). Albumin and $\alpha$-fetoprotein cDNAs hybridized to mRNAs of about $2.2 \mathrm{~kb}$, while $\beta$-major globin cDNA hybridized to mRNA of about $0.6 \mathrm{~kb}$, as previously reported (21). The pattern of hybridization was the same in fetal and adult livers. Mouse liver $\alpha$ fetoprotein cDNA did not cross-hybridize with rat liver.

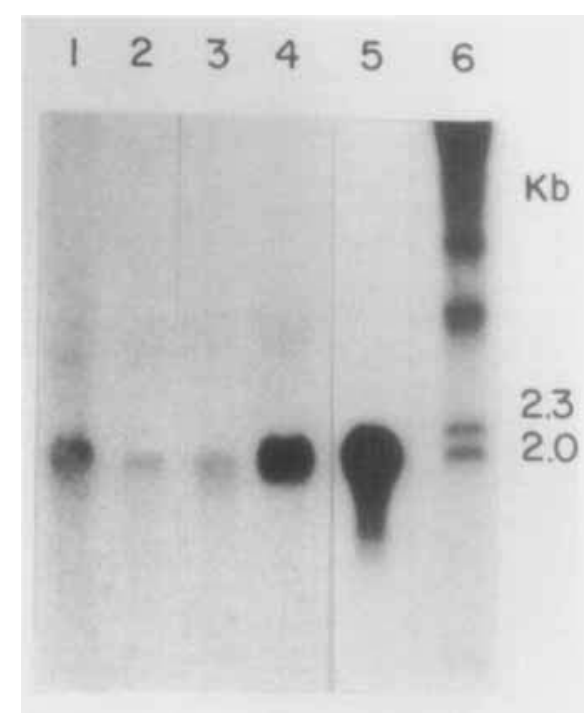

FIG. 1. Northern-blot hybridization analysis: cytochrome $P-450$ b,e, albumin, $\alpha$-fetoprotein and $\beta$-major globin. Ten micrograms of total RNA isolated from livers of developing mice or rats were submitted to electrophoresis in a formaldehyde-denatured agarose gel, transferred to nitrocellulose paper, hybridized with ${ }^{32} \mathbf{P}$-labeled specific cDNAs and analyzed by autoradiography. Lane $1=$ mouse fetal liver, control $(20$ $\mu \mathrm{g}) ;$ Liver $2=$ mouse fetal liver, PB-treated; Lane $3=$ mouse adult liver, control; Lane $4=$ mouse adult liver, $\mathrm{PB}$ treated; Lane $5=$ rat adult liver, PB treated; Lane $6=\lambda$ DNA-size markers. 


\section{mRNA Measurements: Quantitative Dot-Blot Hybridization}

Figure $2 \mathrm{~A}$ shows an autoradiograph depicting the degree of resolution obtained by dot-blot hybridization. Densitometric analysis (laser-activated LKB densitometer) of a representative sample is illustrated in Figure 2B. The area under each peak was integrated (Gelscan program, LKB) and the resulting values plotted to assess the linearity of the assay. The spots on the filter were cut out, counted, the background subtracted and the linearity of the results determined. Figure 2C illustrates the regression lines calculated for three of the samples hybridized with the $\alpha$-fetoprotein $\mathrm{cDNA}$ : fetal liver at 19 days gestation and newborn livers at 3 and 10 days gestation. The same standardization was performed with

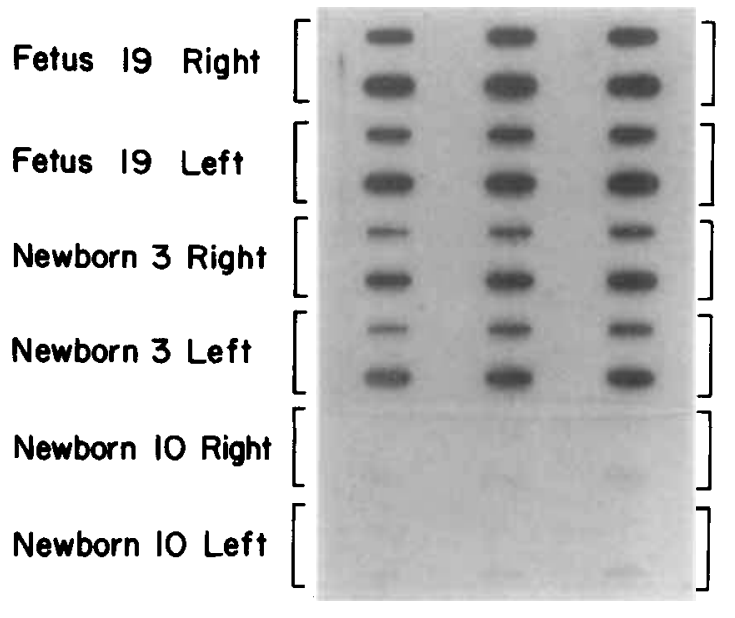

Key:

\begin{tabular}{|c|c|c|}
\hline \multicolumn{3}{|c|}{$\mu \mathrm{g}$ RNA/spot } \\
\hline 0.5 & 0.75 & 1.0 \\
\hline 1.5 & 2.0 & 2.5 \\
\hline
\end{tabular}

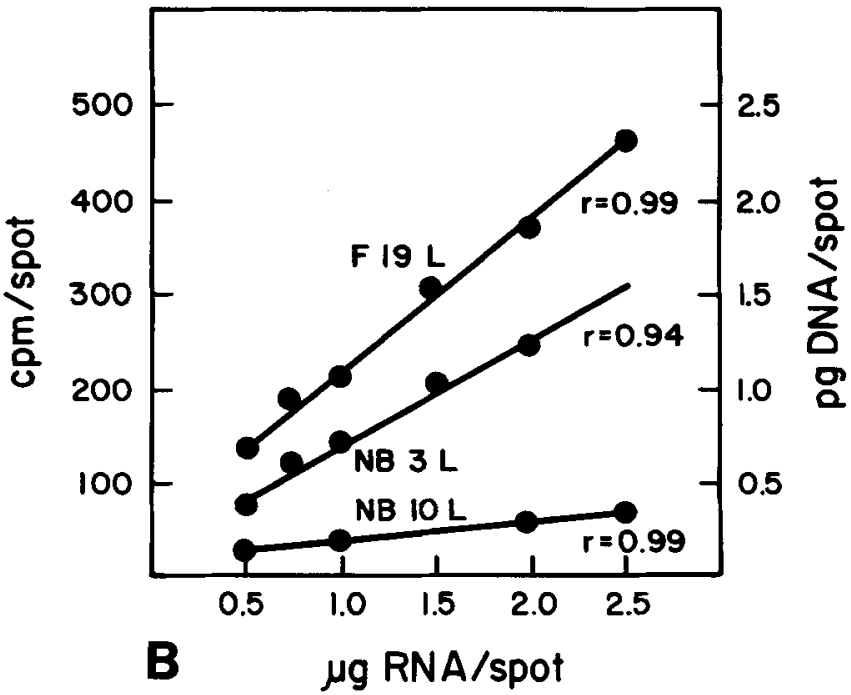

A

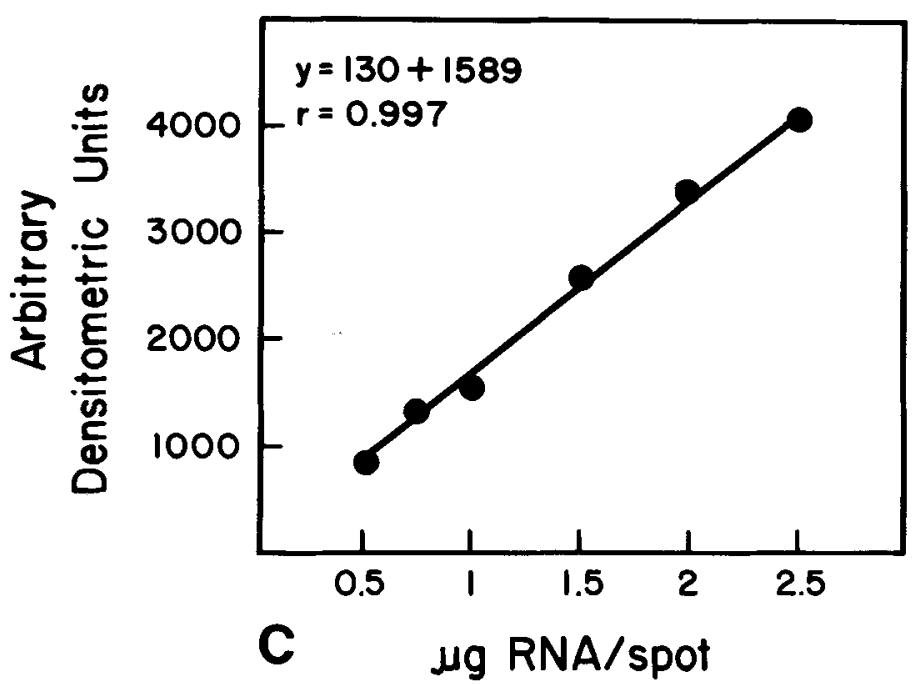

Fig. 2. Standardization of the quantitative dot-blot hybridization assay. Results shown correspond to some of the values obtained during the standardization of the measurements of $\alpha$-fetoprotein mRNA in mouse liver. (A) The autoradiography of RNA samples. Total cellular RNA from each sample was spotted onto the nitrocellulose filter in six concentrations between 0.5 and $2.5 \mu \mathrm{g}$ per spot. Filters were hybridized with 24 $\mathrm{ng}\left[{ }^{32} \mathrm{P}\right] \alpha$-fetoprotein $\mathrm{cDNA}$ per ml hybridization solution. Hybridization solution $(0.1 \mathrm{ml})$ was used per square centimeter of nitrocellulose filter. The specific activity of the probe was $2 \times 10^{8} \mathrm{cpm}$ per $\mu \mathrm{g}$ DNA. The time of exposure of autoradiographs was constant (19 hr). (B) Linear regression analysis. Left ordinate: $\mathrm{cpm}$ per spot $=\mathrm{cpm}$ - background. For each sample, cpm per spot was determined using RNA concentrations between 0.5 and $2.5 \mu \mathrm{g}$ per spot. Background levels were usually between 60 and $90 \mathrm{cpm}$ per spot. Linear regression analysis calculated by the least squares method. Right ordinate: pg DNA per spot $=\frac{\mathrm{cpm} \times 10^{6}}{\text { S.A. } \times \mathrm{e}^{-\mathrm{kt}}} \cdot$ S. A. $=$ specific activity of the cDNA probe in cpm per $\mu \mathrm{g}$ DNA. $\mathrm{e}^{-\mathrm{kt}}=$ correction factor for radioactive decay, where $t=$ time difference (in days) between nick translation and counting, and $\mathrm{k}={ }^{32} \mathrm{P}$ decay constant (0.0485). F $19 \mathrm{~L}=$ fetus 19 days gestation, left liver lobe. NB $3 \mathrm{~L}=$ newborn, 3 days old, left liver lobe. NB $10 \mathrm{~L}=$ newborn, $10 \mathrm{days}$ old, left liver lobe. (C) Densitometric analysis. Each band obtained by autoradiography was quantitated by means of a laser-activated LKB densitometer. Areas under each peak were integrated and the statistical analysis performed using Gelscan (LKB software). The integrated values obtained per each of the six RNA concentrations measured per sample were submitted to a linear regression analysis (as previously described). Values correspond to the levels of $\alpha$-fetoprotein mRNA measured in a sample of RNA extracted from newborn ( 3 days old, left liver lobe). Data have been expressed in arbitrary densitometric units. In the upper left corner of the graph, the equation of the straight line (y) and the correlation coefficient $(r)$ are indicated. 
the albumin and the cytochrome P-450 probes. Since, in every instance, the results obtained by densitometric analysis were the same as those calculated by radioactive counting, the data have been described only in terms of relative densitometric analysis. Hybridization performed using fetal sternum and anterior chest wall RNA gave a faint band, when hybridized with cytochrome P-450 cDNA, which was not measurable either by densitometric analysis nor by assessment of radioactivity. Similarly, hybridizations performed with labeled pBR322 resulted in undetectable values.

\section{Characterization of the Right and Left Fetal mouse Liver Lobes}

Figure 3 shows the vascular pattern assessed by the generation of India ink microcasts. The umbilical vein provides branches to the medial lobe and bifurcates into a branch which represents the ductus venosus (which empties into the inferior vena cava), and a branch which empties into the portal sinus. At this point, branches to the left and caudate lobes are apparent. The portal vein empties into the portal sinus. The branch to the right lobe originates from the portal sinus closer to the entry of the portal vein. This vascular pattern of fetal mouse liver is entirely similar to the vascular patterns of fetal liver described in lambs (1).

Under light microscopy, numerous hematopoietic cells were observed in each fetal lobe. After birth, the number of hematopoietic cells seemed to decrease, and only a few of these cells were observed in 10-day-old newborn livers (data not shown). To assess the relative proportions of hematopoietic cells in each fetal liver lobe, hybridizations were performed with genomic DNA corresponding to the mouse $\beta$-major globin gene. Figure 4 shows that the relative content of $\beta$-globin was similar in each fetal liver lobe, as assessed by quantitative dot-blot hybridization. Figure 5 (A and B) illustrates the changes in weight of the right and left mouse liver lobes as well as that of the

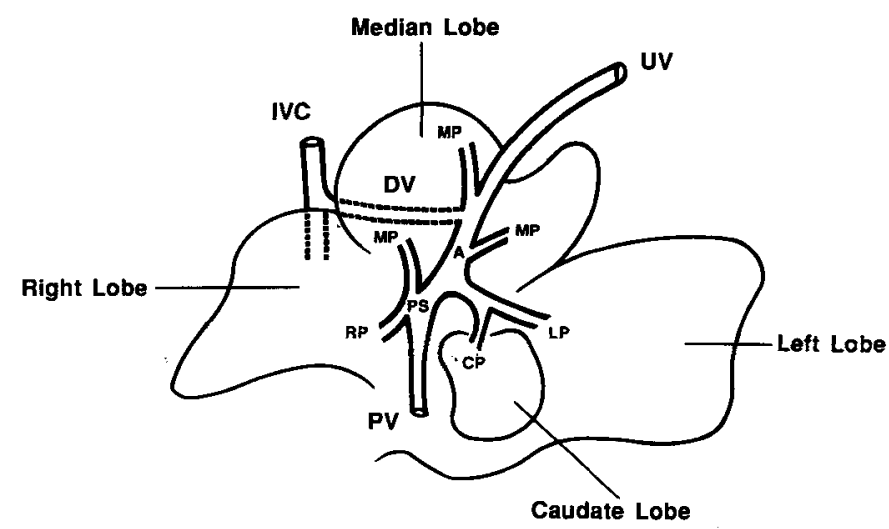

FIG. 3. Anatomical characterization of the vascular pattern in fetal mouse liver. India ink microcasts were performed in mouse liver of 20 days gestation. The umbilical vein (UV) provides branches to the medial lobe (MP) and bifurcates into the ductus venosus (DV) and into a branch (A) which empties into the portal sinus (PS). The ductus venosus empties into the inferior vena cava (IVC). Branches to the left liver lobe (LP) and caudate lobe (CP) originate from the portal sinus. The branch perfusing the right lobe (RP) originates from the portal sinus at the junction with the portal vein (PV).

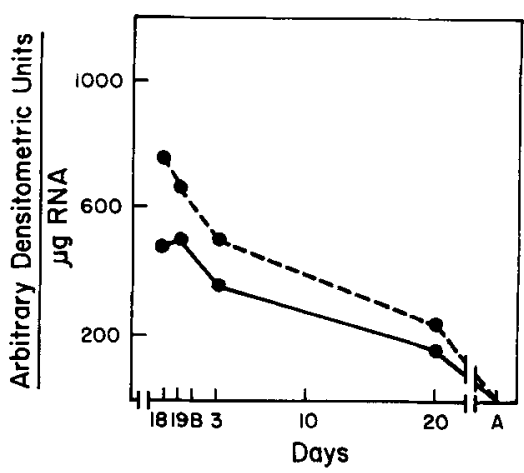

Fig. 4. $\beta$-Major globin $m R N A$ in the right and left liver lobes in developing mice. The relative content of the $\beta$-major globin of the right fetal liver lobe (solid line) and left fetal liver lobe (dotted line) is expressed as arbitrary densitometric units per microgram of RNA. The gestational age at which the sample was obtained is represented in the abscissa. $\mathrm{B}=$ birth; $\mathrm{A}=$ adult.
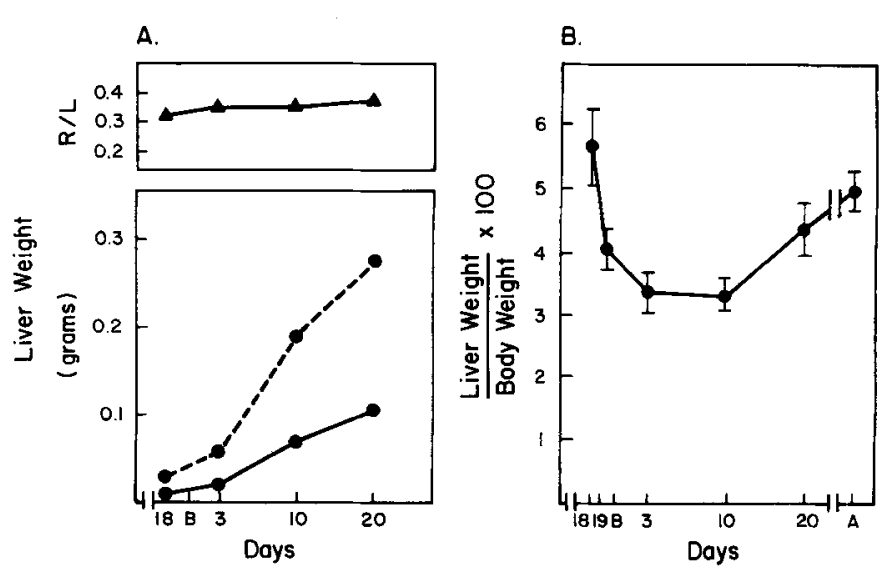

FIG. 5. Liver weight in developing mice. (A) (Upper) $\mathrm{R} / \mathrm{L}=$ ratio right/left liver lobe weight. (Bottom) Right and left fetal liver lobes were removed at various gestational ages (abscissa) and immersed in liquid nitrogen. Seven to 12 right (solid line) or left (dotted line) lobes were pooled, weighed and the total weight divided by the number of liver samples. (B) The ratio of liver/body weight is represented. Each value corresponds to the mean \pm S.D. of at least four animals.

liver weight/body weight ratio with age, respectively. The rate of growth of the right and left liver lobes was similar, as evidenced by the constant ratio right/left liver lobe weight at every age studied. In absolute terms, each lobe increased weight about 8-fold between 18 days gestation and 20 days postnatally. At Day 20 postnatally, the total weight of the liver was about 15 to $20 \%$ that of the adult liver. Interestingly, the liver represented about a $5.7 \%$ of the body weight at 18 days gestation. This ratio liver/ body weight decreased rapidly during the last days of gestation, reaching its lowest value in the immediate postnatal period. By the end of the second week of the newborn period, this ratio increased again until Day 20 when the ratio liver/body weight (about 4.5 to $5.0 \%$ ) was similar to that of the adult mouse. Several unsuccessful attempts were made to sample blood from the umbilical and portal veins of fetal livers in mice and rats. The small size of these fetuses precluded the sampling of blood from each vessel. 


\section{Cytochrome P-450 b,e mRNAs in Control Livers of Developing Mice and Rats}

Since the cytochrome P-450 b,e (R17) cDNA probe was isolated from rat liver, initial experiments determined whether it was possible to measure cytochrome $\mathrm{P}$ $450 \mathrm{~b}$,e mRNAs in rat liver of control fetuses. Figure $6 \mathrm{~A}$ shows that cytochrome P-450 b,e mRNA levels were higher in the left than in the right rat fetal liver lobes at Days 17, 18 and 19 gestation, although these differences decreased towards birth. Figure $6 \mathrm{~B}$ shows that when the same poly $\left(\mathrm{A}^{+}\right) \mathrm{RNA}$ material was hybridized with the albumin cDNA, the relative levels of albumin mRNA were similar in the right and left rat fetal liver lobes.

Having established that cytochrome P-450 b,e genes were expressed in fetal rat liver, expression in mouse liver was studied. Initial quantitative dot-blot hybridization experiments performed with mouse liver showed only faint bands. Since the amount of RNA extracted from the right and left fetal liver lobes in mice precluded the separation of poly $\left(\mathrm{A}^{+}\right) \mathrm{RNA}$, the labeling of the cytochrome P-450 b,e (R17) cDNA was increased by using the Klenow fragment labeling method (22). Figure 7A shows the autoradiograph of the quantitative dot-blot hybridization. As shown, signals were clearly measurable. Figure 7B shows the densitometric assessment of the quantitative dot-blot. In agreement with the data obtained in fetal rat liver, the left fetal lobe of control mouse liver also contained higher levels of cytochrome P-450 b,e mRNAs than the right fetal lobe. These differences between the right and left liver lobes were apparent until Day 10 of the postnatal period when the levels of $\mathrm{P}-450 \mathrm{~b}, \mathrm{e}$ mRNAs became similar. Of interest, the levels of cytochrome P-450 b,e mRNAs in the left lobe were higher in fetal liver than at later ages. Actually, the higher level of cytochrome P- $450 \mathrm{~b}$,e mRNA expressions observed during the last days of gestation and immediately postnatally was predominantly due to the mRNA content of the left lobe.

Cytochrome P-450 b,e mRNA after PB Administration: As shown in Figure 8A, increments in the levels of mouse liver cytochrome P-450 b,e mRNAs were not clearly apparent, in either of the lobes, after the admin-
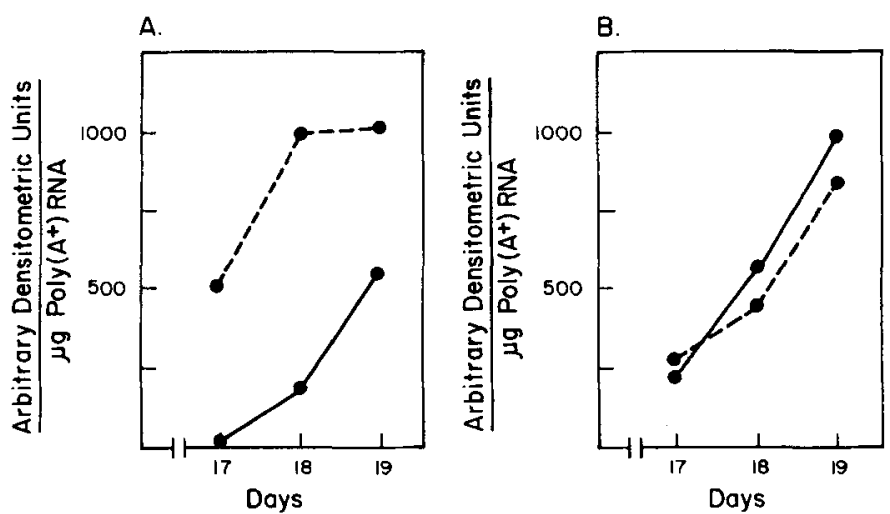

Fig. 6. Cytochrome P-450 b,e mRNAs and albumin mRNA in the right and left liver lobes of control rats. The abscissa illustrates the gestational age at which the poly $\left(\mathrm{A}^{+}\right) \mathrm{RNA}$ was obtained. The same poly $\left(\mathrm{A}^{+}\right) \mathrm{RNA}$ was hybridized either with the cytochrome $\mathrm{P}-450$ probe (A) or with the albumin probe (B). Solid line = right lobe; dotted line $=$ left lobe.
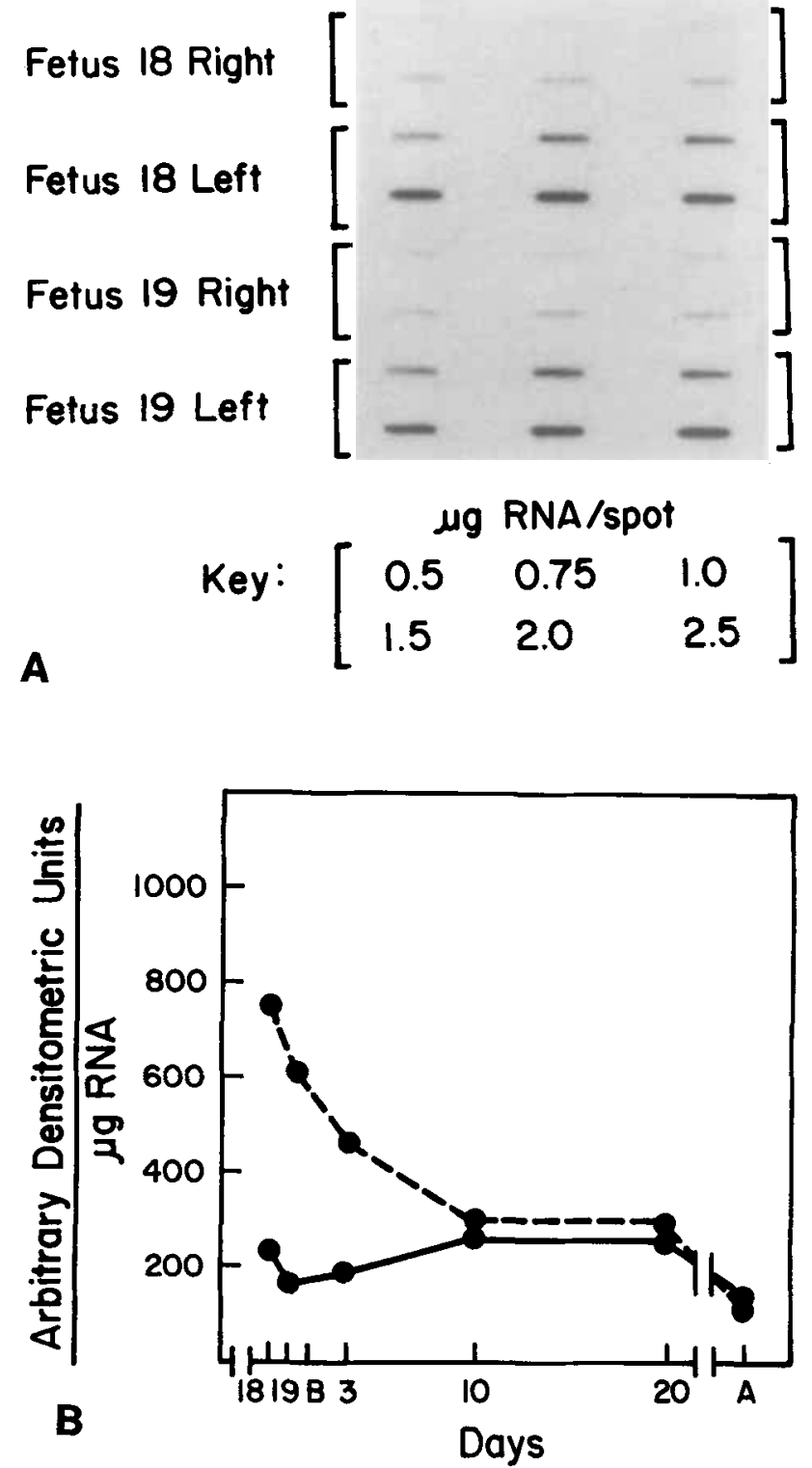

FIG. 7. Cytochrome $P-450$ b,e mRNAs in the right and left liver lobes of control mice. (A) Autoradiography of the dot-blot hybridization. Thirty nanograms of R17 cDNA insert per milliliter of hybridization solution were used in these hybridizations. The DNA probe was labeled by the oligolabeling method using the Klenow fragment to a specific activity of $2 \times 10^{\circ}$. (B) Relative content of the cytochrome P.450 b,e mRNAs in the right and left liver lobes of developing control mice. $B$ $=$ birth; $\mathrm{A}=$ adult; solid line = right lobe; dotted line = left lobe.

istration of a single dose of PB to the mother. Maximal levels of these mRNAs in response to $P B$ were observed at Day 3 postnatally. Both liver lobes responded to PB similarly. Similar findings were observed when the rat liver was studied after PB administration (Figure 8B).

\section{$\alpha-F e t o p r o t e i n$ and Albumin mRNA Levels in the Right and Left Liver Lobes}

Figure 9A shows that the levels of albumin mRNA were expressed to similar levels in the right and left mouse fetal liver lobes. Interestingly, and in agreement with the findings observed with cytochrome $\mathrm{P}-450 \mathrm{~b}, \mathrm{e}$ as well as with $\alpha$-fetoprotein, the levels of albumin mRNA 

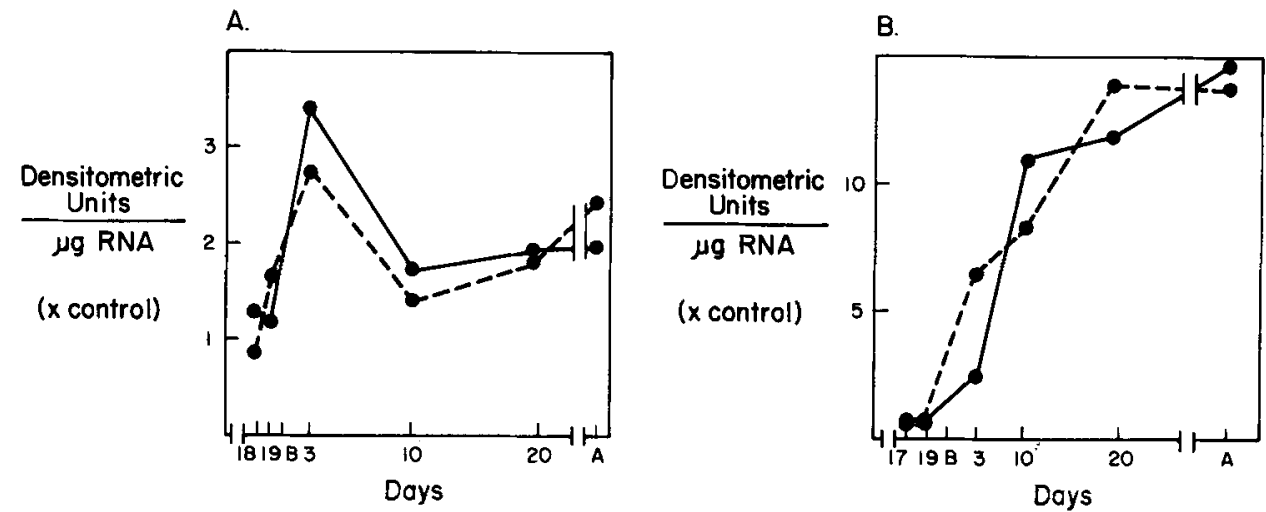

Fig. 8. Cytochrome $P-450$ b,e $m R N A$ in developing mice and rats after $P B$ administration. $P B(60 \mathrm{mg} \times \mathrm{kg}$, i.p.) was administered as a single injection, $16 \mathrm{hr}$ prior to the experiments. $\mathrm{PB}$ was injected into timed-pregnant mice and rats, and into newborns and adults. $\mathrm{B}=$ birth; $\mathrm{A}=$ adults; solid line = right lobe; dotted line = left lobe. (A) Relative content of cytochrome P-450 b,e mRNAs in mice. (B) Relative content of cytochrome P-450 b,e mRNAs in rats.

A.

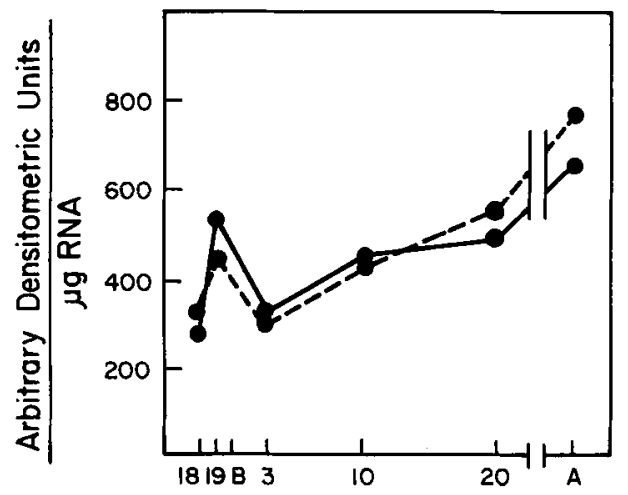

B.

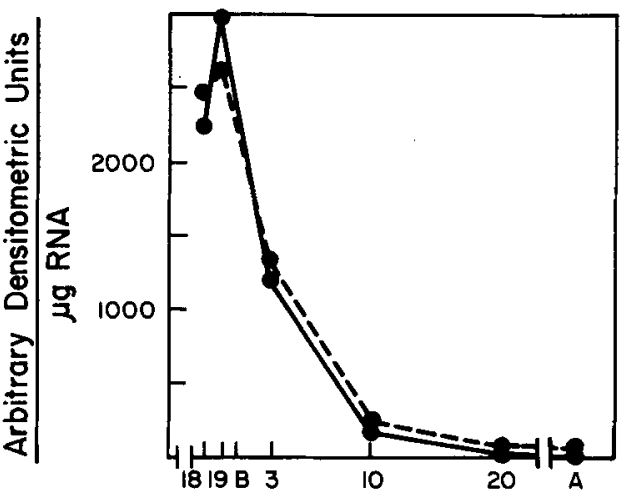

FIG. 9. $\alpha$-Fetoprotein and albumin mRNAs levels in the right and left liver lobes in mice. Hybridizations were performed using cDNA-specific probes labeled by nick translation. In these experiments, $40 \mathrm{ng}$ cDNA per ml hybridization solution were used. $\mathrm{B}=\mathrm{birth}$; $\mathrm{A}=\mathrm{adult}$; solid line $=$ right lobe; dotted line = left lobe. (A) Relative content of albumin mRNA. (B) Relative content of $\alpha$-fetoprotein mRNA.

increased immediately prior to birth and decreased in the early postnatal period. Values close to those measured in the adult liver were observed by the end of the third week. Figure 9B shows that $\alpha$-fetoprotein mRNA levels were also expressed simultaneously and similarly in each mouse fetal liver lobe. Levels of expression of this mRNA were high by Day 18 of gestation, slightly increased by Day 19 , to decrease rapidly and similarly in both liver lobes after birth. By Day 20 postnatally, the levels of $\alpha$-fetoprotein mRNA reached values similar to those found in adult mouse liver.

\section{DISCUSSION}

In the transition from fetal to the adult pattern of gene expression, there are at least three regulatory steps: (a) regulation of gene expression during fetal life, when liver lobes are perfused differently; (b) expression of genes during the transition from fetal to newborn liver, a step of development during which major changes in liver circulation occur, and (c) the maturation of the newborn liver into an adult pattern of expression. In this study, the expression of the cytochrome P-450 b,e, albumin and $\alpha$-fetoprotein genes has been defined in the right and left liver lobes of fetal and newborn livers. The rationale for this approach was that there is ample evidence that, in every mammal studied (2-5), the right and left fetal liver lobes constitute distinct functional units. Attempts were made to determine the composition of the blood carried by the umbilical and fetal portal veins of mice and rats. The size of these fetuses, however, precluded adequate blood sampling. Therefore, in interpreting some of the results, the assumption has been made that the composition of the blood perfusing the right and left fetal liver lobes of mice and rats was indeed different. This assumption is supported by the finding that the vascular pattern of the mouse fetal liver was entirely similar to that of larger mammals (i.e., that the portal vein emptied into the portal sinus where branches to the right fetal lobe originated).

The conditions defined in the quantitative dot-blot assay used in this study secured that every mRNA measurement was performed while the cDNA probe was in excess. Furthermore, the reproducibility of the amount of RNA loaded into filters, the blotting procedure and the hybridization were assessed in each filter by also running an internal standard in six concentrations. This allowed us to define the linearity and slope of the standard as well as that of each sample. Northern-blot analysis 
confirmed that the size of the hybridizable RNA in fetal livers was similar to that hybridized with the cytochrome $\mathrm{P}-450 \mathrm{~b}, \mathrm{e}$ (R17) insert in adult liver.

The results of this study suggest that there are differences in the levels of expression of the cytochrome $\mathrm{P}$ $450 \mathrm{~b}$,e mRNAs in the fetal liver lobes. The left lobe of mouse liver, the one perfused with blood carrying a higher oxygen concentration and presumably, rich in maternal hormones, had higher levels of the P-450 mRNAs than the right fetal lobe at 18 and 19 days gestation. Actually, the rise in the levels of cytochrome P-450 b,e mRNAs prior to birth was due entirely to the contribution to these measurements of the mRNA present in the left fetal liver lobe. Similar findings were observed in fetal rat liver. These results indicated that the cytochrome P-450 b,e genes were expressed in fetal livers of control mice and rats. This finding was in contrast to a recent study in which the expression of these genes in whole fetal liver was determined using specific oligonucleotides (25). In that study, cytochrome P-450 b or e gene expression was not detected in control fetal livers before Day 22 of gestation (25). We believe that the reasons for this discrepancy are that in that study, cytochrome P-450 b,e mRNAs were measured separately by each oligonucleotide. Since the insert used as a probe in our work recognized sequences of both cytochromes, we measured the sum of both mRNAs. In addition, the selective measurement of cytochromes $P$ $450 \mathrm{~b}, \mathrm{e}$ mRNAs in the left lobe rather than in total liver increased the relative content (specific $\mathrm{mRNA} /$ total RNA) of these cytochromes and thus the likelihood of detection.

These results suggested that the microenvironments surrounding hepatocytes in each lobe may play a role regulating the expression of the cytochrome $\mathrm{P}-450 \mathrm{~b}, \mathrm{e}$ genes in fetal liver. The finding that cytochrome P-450 b,e genes were expressed in high levels in the left fetal liver lobe may have biological importance, since the left fetal liver lobe receives the main flow of blood coming via the umbilical veins and thus, potentially rich in endogenous and exogenous substances which have crossed the placental barrier. In this context, it has been proposed that steroids may represent endogenous substrates for these cytochromes (26). Attempts were made to assess these differences between the right and left fetal liver lobes at earlier times of gestation (i.e., at 16 days gestation in mice and at 15 days in rats). However, the small size of the liver at this stage, precluded the separation of the right lobe from the remainder of the liver parenchyma.

It has been shown that, late in fetal life, about 40 to $50 \%$ of liver cells are hematopoietic cells (27). Furthermore, on the basis of qualitative morphological assessment (6), it was proposed that the content of hematopoietic cells in human fetal liver was higher in the right than in the left fetal and newborn liver lobes. If this proposal was valid for mouse liver, it was plausible that lower levels of cytochrome P-450 b,e mRNAs may have been measured in the right fetal liver lobe in our experiments because of a relative larger number of hematopoietic cells in this lobe. However, measurements of $\beta$ globin mRNA indicated that the relative content of this
mRNA, and thus of hematopoietic cells, was similar in the right and left fetal liver lobes. Therefore, it is unlikely that differences in the content of hematopoietic cells between the right and left fetal liver lobes explain the differences in the levels of cytochrome P- $450 \mathrm{~b}, \mathrm{e}$ mRNAs observed in fetal liver. Moreover, the levels of $\alpha$-fetoprotein and albumin mRNA, measured in the right and left fetal mouse liver lobes using the same RNA samples used in cytochrome P-450 mRNA determinations, were similar, suggesting that it was unlikely that differences in recovery of RNA may explain the differences observed with cytochrome P-450. An alternative explanation for these results is the possibility that the expression of the cytochrome P-450 e family (26) is different in fetal and adult liver (i.e., that certain members of the cytochrome P-450 e family are expressed only at a certain age during development). The cytochrome P-450 b,e (R17) cDNA probes used in our experiments did not allow us to recognize the possible expression of other individual members of this family.

There have been conflicting reports concerning the inducibility of cytochrome $\mathrm{P}-450$ proteins by $\mathrm{PB}$ during fetal life (28-30). In this study, the administration of PB to the mother did not result in a clear-cut induction in the levels of cytochrome P-450 b,e mRNAs in either of the mouse fetal liver lobes even though it has been shown that barbiturates cross the placental barrier (10). PB induced cytochromes $\mathrm{P}-450 \mathrm{~b}, \mathrm{e}$ mRNAs in the postnatal period. Of interest, in these experiments, the pattern of response to $\mathrm{PB}$ was somehow different between mouse and rat livers. The lower degree of PB-mediated cytochrome P-450 induction observed in mouse liver was in agreement with previous data obtained in that species in adult liver (23).

The expression of the albumin and $\alpha$-fetoprotein genes have been well-characterized in the developing mouse liver (24). In that study (24), both genes were active in fetal life, thus discrediting the proposal for reciprocal expression of the $\alpha$-fetoprotein and albumin genes in developing liver. However, those experiments did not rule out the possibility that these two genes may have been expressed at different times of gestation in different lobes of the fetal liver, giving the impression, when analyzed in whole liver, that expression occurred simultaneously in all hepatocytes. In this study, albumin and $\alpha$-fetoprotein genes were expressed simultaneously and similarly in the right and left fetal liver lobes, supporting previous proposals for a simultaneous expression of these two genes in fetal liver (24). In addition, the changes in mRNA levels with age were the same as those previously described (24). To the extent that the assumption previously mentioned is correct (i.e., that the perfusion of the right and left fetal mouse liver lobes is performed with blood of different composition), these results indicate that the difference in oxygen content of bloodbathing hepatocytes do not exert a major regulatory effect on albumin and $\alpha$-fetoprotein gene expression in fetal liver.

Also relevant to the understanding of the attainment of the adult characteristics of the liver was the assessment of the changes in liver weight in each functional unit. The weight of the right and left liver lobes increased 
with age at the same rate as indicated by a constant right/left liver weight ratio. In absolute terms, total liver weight increased about 8- to 10 -fold between Day 18 of gestation and Day 20 postnatally. Total liver weight at Day 20 was still about 15 to $20 \%$ the weight of the adult mouse liver. However, the expression of the cytochrome $\mathrm{P}-450 \mathrm{~b}$,e genes in control mice as well as the response to PB had already attained a pattern similar to that of the adult. This was also the case for the albumin and $\alpha$ fetoprotein genes. To this extent, liver "maturation" [as defined by the relative proportion of the specific mRNAs (specific mRNAs/total RNA)] seemed to have been attained for these genes during the first 3 to 4 weeks of extrauterine life. It should be noted, however, that the developmental course of expression of mRNAs seems to be gene-specific rather than age-specific (31).

In conclusion, the experiments performed in this study with the PB-inducible cytochrome P- 450 b,e genes in the developing mouse liver indicated that these genes were expressed heterogeneously in the two functional units of the fetal liver: the right and left liver lobes. During the transition from fetal to newborn liver, important changes in regulation of gene expression occurred. First, the differences in expression of these genes between the right and left liver lobes disappeared, and second, the capacity for response to PB with the induction of cytochrome P$450 \mathrm{~b}, \mathrm{e}$ mRNAs became evident. It is plausible that the differences in the expression of the cytochrome P-450 $b, e$ mRNAs in the right and left fetal liver lobes may depend on the presence of substances (oxygen, steroidal hormones and inducers which traversed the placental barrier) in umbilical vein blood.

Acknowledgment: The authors wish to thank Dr. Miriam Meisler from the Department of Human Genetics of the University of Michigan for reviewing this manuscript.

\section{REFERENCES}

1. Rudolph AM. Hepatic and ductus venosus blood flows during fetal life. Hepatology $1983 ; 3: 254-258$.

2. Lind J. Changes in the liver circulation at birth. Ann NY Acad Sci 1963; 111:110-120.

3. Barclay AE, Franklin J, Prichard MML. The fetal circulation and cardiovascular system and the changes that they undergo at birth. Springfield, Illinois: Charles C Thomas, 1945: 275-290.

4. Reuss ML, Rudolph AM. Selective distribution of microspheres injected into the umbilical venous and inferior vena cavae of fetal sheep. Am J Obstet Gynecol 1981; 147:427-431.

5. Zink J. The Fetal and Neonatal Hepatic Circulation. In: Lautt W, ed. Hepatic circulation in health and disease. New York: Raven Press, 1981: 227-256.

6. Emery JL. Functional asymmetry of the liver. Ann NY Acad Sci 1963; 111:37-44.

7. Edelstone DI. Regulation of blood flow through the ductus venosus. J Develop Physiol 1980; 2:219-238.

8. Edelstone DI, Rudolph AM, Heymann MA. Effect of hypoxemia and decreasing umbilical flow on liver and ductus venosus blood flow in fetal lambs. Am J Physiol 1980; 238:H656-H663.

9. Divorchick BH, Senteger VG, Quattropani SL. Drug biotransfor- mation in microsomes from the fetal stumptailed macaque, Macaca arctoides: hepatic- $N$-demethylation. Drug Metab Dispos 1976; 4:423-429.

10. Finster M, Morishima HO, Mark LC, et al. Tissue thiopental concentrations in the fetus and newborn. Anesthesiology 1972; 36:155-163.

11. Mihaly GW, Morgan DJ, Smallwood R, et al. The developing liver: the steady-state disposition of propanolol in pregnant sheep. Hepatology 1982; 2:344-349.

12. Chianale J, Dvorak C, May M, et al. Heterogeneous expression of phenobarbital-inducible cytochrome $\mathrm{P}-450$ genes within the hepatic acinus in the rat. Hepatology 1986; 6:945-951.

13. Hardwick JP, Gonzalez FJ, Kasper CB. Transcriptional regulation of rat liver epoxide-hydratase, NADPH-cytochrome P-450 oxidoreductase and cytochrome P-450 genes by phenobarbital. J Biol Chem 1983; 258:8081-8085.

14. Chirgwin JM, Przybyla AE, McDonald RJ, et al. Isolation of biologically active ribonucleic acid from sources enriched in ribonuclease. Proc Natl Acad Sci USA 1979; 18:5294-5299.

15. Werner D, Chemla Y, Herzberg $M$. Isolation of poly $\left(\mathrm{A}^{+}\right) \mathrm{RNA}$ by paper affinity chromatography. Anal Biochem 1984; 141:392-336.

16. Wreschner $\mathrm{DH}$, Herzberg $M$. A new blotting medium for the simple isolation and identification of highly resolved messenger RNA. Nucleic Acid Res 1984; 12:1349-1360.

17. Maniatis T, Fritsch EF, Sambrook J. Molecular cloning. A laboratory manual. New York: Cold Spring Harbor Laboratory, 1982: 202-203.

18. Papavasiliou SS, Zmeili S, Herbon L, et al. Alpha and luteinizing hormone beta messenger ribonucleic acid (RNA) of male and female rats after castration: quantitation using an optimized RNA dot blot hybridization assay. Endocrinology 1986; 119:691-697.

19. White BA, Bancroft C. Cytoplasmic dot hybridization. J Biol Chem 1982; 257:8569-8573.

20. Adesnik M, Bar-Non S, Maschio F, et al. Mechanism of induction of cytochrome P-450 by phenobarbital. J Biol Chem 1981; 256:10340-10345.

21. Rigby PWJ, Dieckmann M, Rhodes M. Labelling deoxyribonucleic acid to high specific activities in vitro by nick translation with DNA polymerase I. J Molec Biol 1977; 113:237-251.

22. Feinberg AP, Vogelstein B. Technique for radiolabeling DNA restriction endonuclease fragments to high specific activity. Anal Biochem 1982; 132:6-13.

23. Stupans I, Ikeda T, Kessler DJ, et al. Characterization of a cDNA clone for mouse phenobarbital-inducible cytochrome P-450 b. DNA 1984; 3:129-137.

24. Tilghman SM, Belayew A. Transcriptional control of the murine albumin $/ \alpha$-fetoprotein locus during development. Proc Natl Acad Sci USA 1982; 79:5254-5257.

25. Giachelli CM, Omiecinski CJ. Regulation of cytochrome P-450 b and P-450 e mRNA expression in the developing rat. J Biol Chem $1986 ; 261: 1359-1363$.

26. Adesnik M, Atchison M. Genes for cytochrome P-450 and their regulation. CRC 1986; 19:247-305.

27. Greengard O, Federman M, Knox WE. Cytomorphometry of developing rat liver and its application to enzymic differentiation. $J$ Cell Biol 1982; 52:261-272.

28. Cresteil T, Le Provost E, Flinois JP, et al. Enzymatic and immunological evidences that phenobarbital induces cytochrome P-450 in fetal and neonatal rat liver. Biochem Biophys Res Commun $1982 ; 106: 823-830$.

29. Cresteil T, Beaume $P$, Celier $C$, et al. Cytochrome $P-450$ isoenzyme content and monooxygenase activities in rat liver: effect on ontogenesis and pretreatment by phenobarbital and 3-methylcholanthrene. J Pharm Exp Therap 1986; 236:269-276.

30. Phillips IR, Shepard EA, Rabin BR, et al. Factors controlling the expression of genes coding for drug-metabolizing enzymes. Biochem Soc Trans 1983; 11:460-463.

31. Barth RK, Gross KW, Gremke LC et al. Developmentally regulated mRNAs in mouse liver. Proc Natl Acad Sci USA 1982; 79:500-504. 